\title{
High-speed operation in printed organic inverter circuits with short channel length
}

\author{
Yudai Yoshimura $^{1,2}$, Yasunori Takeda ${ }^{1,2}$, Kenjiro Fukuda $^{1,2}$, Daisuke Kumaki ${ }^{1,2}$, and \\ Shizuo Tokito ${ }^{1,2}$ \\ ${ }^{1}$ Graduate School of Science and Engineering, Yamagata University, 4-3-16 Jonan, \\ Yonezawa, Yamagata, 992-8510, Japan \\ ${ }^{2}$ Research Center for Organic Electronics, Yamagata University \\ Address correspondence to: fukuda@yz.yamagata-u.ac.jp
} http://www.elsevier.com/open-access/userlicense/1.0/ 


\begin{abstract}
We have demonstrated fast operation of printed organic inverter circuits. We employ a soluble organic semiconducting material which has high field-effect mobility and ink-jet printed source/drain electrodes with short channel length. Appropriate concentration of the semiconducting solution and modification layer of source/drain electrodes improve both mobility and on/off ratio. The fabricated transistors with a short channel length $(4 \mu \mathrm{m})$ exhibit excellent mobility $\left(1.2 \mathrm{~cm}^{2} / \mathrm{Vs}\right)$, high on/off ratio $\left(>10^{5}\right)$ and operational stability. The diode-load inverter with a narrow channel and low parasitic capacitance operate at $8 \mathrm{kHz}$ at $20 \mathrm{~V}$. These results will lead to significant progress in applications of printed organic circuits.
\end{abstract}




\section{INTRODUCTION}

Applied research on organic electronics is accelerating with the aim of developing low-cost flexible devices that have large areas. Organic materials have two significant advantages. They possess intrinsic mechanical flexibility due to loose Van der Waals bonds between their organic molecules. In fact, ultra-flexible electronics have been demonstrated [1,2]. Another advantage is solubility in organic solvents; this makes organic materials more suitable than inorganic materials for printing processes. Organic devices can also be used to realize new kinds of electrical devices; besides flexible displays [3-5], these include large-area sensors [6-8] and flexible radio-frequency identification (RFID) tags $[9,10]$. Moreover, there are several reports on organic integrated circuits such as inverters [11-13], ring oscillators [14-16], flip-flops [17], and four-input multiplexers [18]. However, the characteristics of these circuits will have to be improved before they can be put to commercial use.

Specifically, operating speed is an issue for organic circuits. Here, the operating frequency is largely dependent on the channel length, i.e., [19]

$$
f_{t}=\frac{\mu_{e f f}\left(V_{G S}-V_{T H}\right)}{2 \pi L\left[L+2\left(L_{C}+L_{e x t}\right)\right]}
$$

where $f_{\mathrm{T}}$ is cutoff frequency, $\mu_{\mathrm{eff}}$ is effective charge-carrier mobility, $V_{\mathrm{GS}}$ is gate-source voltage, $V_{\mathrm{TH}}$ is threshold voltage, $L$ is channel length, $L_{\mathrm{C}}$ is contact length, and $L_{\mathrm{ext}}$ is extended contact length. Equation (1) clearly indicates that both a short channel length and high effective mobility can provide fast operation of integrated circuits. Although organic integrated circuits with channel lengths of less than $5 \mu \mathrm{m}$ and operating frequencies above $1 \mathrm{MHz}$ [20,21] have been reported, their source/drain electrodes were 
fabricated with conventional thermal evaporation and photolithography processes, not printing.

In the case of source/drain electrodes formed by a printing process, the channel length is generally longer than those fabricated by photolithography because of the lack of positioning accuracy and spread of the printed ink. Though there are several reports on printed organic thin-film transistor (TFT) devices with short channel lengths (less than $10 \mu \mathrm{m}$ ) [22-24], the estimated field-effect mobility was only $0.1 \mathrm{~cm}^{2} / \mathrm{Vs}$ because of the large contact resistance $\left(R_{\mathrm{C}}\right)$. Furthermore, the operation speeds of printed integrated circuits with such short-channel-length TFT devices have yet to be reported. It is thus very important to investigate the operational speeds of printed organic TFT devices with high field-effect mobility and short-channel-length transistors and to evaluate the dynamic responses of integrated circuits using these devices.

In this study, we fabricated inverter circuits based on printed organic TFT devices using a high mobility organic semiconductor materials and short channel lengths. We investigated two ways of improving the transistor characteristics: optimization of the organic semiconductor concentration in a solution (ink) and a self-assembled monolayer (SAM) treatment of the source/drain electrodes. We found that the electrical performance of the organic TFT devices strongly depended on the concentration of the semiconducting solution. We obtained high-quality organic semiconductor film from an optimized solution and realized organic TFT devices with a short channel length (less than $10 \mu \mathrm{m})$ that had high mobility $\left(1.2 \mathrm{~cm}^{2} / \mathrm{Vs}\right.$ ), high on/off ratio $\left(>10^{5}\right)$, and high operational stability. These OTFT devices led to a significant 
improvement in the dynamic response of the inverter circuits.

\section{EXPERIMENTAL}

Figure 1(a) and (b) show a schematic illustration and photograph of a fabricated bottom-gate, bottom-contact organic TFT device. These devices were fabricated by evaporating $\mathrm{Al}$ onto a glass substrate to form a 30 -nm-thick gate electrode. A 440-nm-thick cross-linked poly-4-vinylphenol (PVP) (Mw 25000, Sigma Aldrich Co.) layer was then prepared. PVP and poly(melamine-co-formaldehyde) (Sigma Aldrich Co.) as a cross-linking agent were mixed in propylene glycol monomethyl ether acetate (PGMEA). The solution was deposited by spin-coating onto the gate electrodes and dried at $150^{\circ} \mathrm{C}$ for $1 \mathrm{~h}$. Silver nanoparticle ink (NPS-JL, Harima Chemicals) was patterned with an inkjet printer (Fujifilm Dimatix, model DMP2831) to form the source/drain electrodes. The droplets were deposited with a dot-to-dot spacing of $60 \mu \mathrm{m}$. During the inkjet patterning process, the substrate temperature was maintained at $60^{\circ} \mathrm{C}$. After the printing process, the substrates were heated at $120^{\circ} \mathrm{C}$ for 1 hour to sinter the printed silver nanoparticles. The self-assembled monolayer (SAM) treatment for source/drain electrodes was prepared by immersing the substrates in a $5 \mathrm{mM}$ propanol solution of pentafluorobenzenethiol (PFBT) for $5 \mathrm{~min}$ at room temperature. The substrates were then rinsed with pure propanol and blown dry with nitrogen. The SAM treatment changed the work function of the printed silver source/drain electrodes from $4.7 \mathrm{eV}$ to $5.4 \mathrm{eV}$ (see figure $\mathrm{S} 1$ ). Then, a $1 \mathrm{wt} \%$ solution of fluoropolymer (DuPont ${ }^{\mathrm{TM}}$, Teflon $^{\circledR}$ AF 1600,) in Fluorinert ${ }^{\mathrm{TM}}\left(3 \mathrm{M}^{\mathrm{TM}}\right.$ FC-43) was used as a bank layer and printed by using dispenser equipment (Musashi Engineering, Image Master $350 \mathrm{PC}$ ) that 
included a three-axis table and an air dispenser, both of which were computer-controlled to dispense and pattern the solution. 200-nm-thick fluoropolymer bank layers were printed at a patterning speed of $20 \mathrm{~mm} / \mathrm{s}$ and discharge pressure of $7 \mathrm{kPa}$, and they were subsequently cured at $40^{\circ} \mathrm{C}$ for $5 \mathrm{~min}$ in air. The bank size was $2000 \mu \mathrm{m} \times 1000 \mu \mathrm{m}$. Finally, a mesitylene-based formulation for the organic semiconducting layer (Merck, lisicon ${ }^{\circledR} \mathrm{S} 1200$ ) [25-27] with a deep ionization potential of $5.4 \mathrm{eV}$ was drop-casted into the bank layers. The volume of each droplet was $1 \mu \mathrm{l}$ for all devices. After deposition, the substrates were annealed at $100^{\circ} \mathrm{C}$ for $1 \mathrm{~min}$ in air. We prepared several solutions with different semiconducting concentrations (from 0.01 to $2.0 \mathrm{wt} \%$ ) in order to optimize the electrical performance of the fabricated TFT devices. Figure 1(c) shows a magnified optical image of the channel region of a fabricated TFT device with a short channel length $(L=4 \mu \mathrm{m})$. The electrical properties of the organic TFT devices were measured using a semiconductor parameter analyzer (4200SCS, Keithley Instruments) under dark conditions in ambient air.

\section{RESULTS AND DISCUSSION}

\subsection{Change in characteristics with the concentration of organic semiconductor}

First, we optimized the concentration of the semiconducting solution. Figure 2 (a) shows the transfer characteristics of the TFTs whose semiconducting layer was formed from $0.01,0.05,0.1$ or $2.0 \mathrm{wt} \%$ solutions. The devices had almost the same channel widths $(1000 \mu \mathrm{m})$ and lengths $(23 \mu \mathrm{m}$ ave. $)$. The gate voltage $\left(V_{\mathrm{GS}}\right)$ was swept from +10 to $-20 \mathrm{~V}$ while the drain-source voltage $\left(V_{\mathrm{DS}}\right)$ was kept at $-20 \mathrm{~V}$. These 
transfer curves clearly show that the electrical performance of the TFT devices strongly depends on the concentration of the semiconducting solution. Figures 2 (b)-(d) show the relationship between concentration and mobility, threshold voltage, and on/off ratio. The dots represent the average value for eight samples, and the length of the error bars represents the standard deviation of each value. Figure 2(b) shows that increasing the concentration from 0.01 to $0.05 \mathrm{wt} \%$ caused the mobility to increase from $0.04 \mathrm{~cm}^{2} / \mathrm{Vs}$ to $0.38 \mathrm{~cm}^{2} / \mathrm{Vs}$ at $0.05 \mathrm{wt} \%$, while further increasing the concentration to $2.0 \mathrm{wt} \%$ caused the mobility to drop to $0.06 \mathrm{~cm}^{2} / \mathrm{Vs}$. Figure 2(c) indicates that the threshold voltage shifts in the negative direction as the concentration increases from $0.01 \mathrm{wt} \%$ to $1 \mathrm{wt} \%$, whereas the threshold voltages of the devices made with the $2.0 \mathrm{wt} \%$ concentration varied from device to device. As shown in figure 2(d), the on/off ratio improved from $3.7 \times 10^{5}$ to $3.3 \times 10^{6}$ with increasing concentration from 0.01 to 0.05 $\mathrm{wt} \%$, whereas it dropped rapidly to $10^{2}$ upon further increasing the concentration to 2.0 wt\%. A rapid increase in off current caused the decrease in the on/off ratio at higher concentrations. To evaluate the effect of semiconducting crystallinity on transistor performance, we observed the channel region of the TFT devices with a polarizing microscope and estimated the difference in the crystallinities of the semiconducting layers at each concentration. Figure 3 shows the channel regions of TFT devices made with $0.01,0.05,0.1$, and $2.0 \mathrm{wt} \%$ solutions. As shown in figure $3(\mathrm{a})$, the high concentration solution ( $2 \mathrm{wt} \%)$ made thick semiconducting films near the edge of the bank, which was a result of a coffee-ring effect [28] and made needle-like crystalline structures at the center of the bank layer. The needle-like crystalline structures were even in the semiconducting film made with the $0.1 \mathrm{wt} \%$ solution (Fig. 3b), but not in the films made with less than $0.1 \mathrm{wt} \%$ solution. Relatively uniform and large crystalline 
domains (approximately $30 \mu \mathrm{m}$ ) were formed at $0.05 \mathrm{wt} \%$ (Fig. 3c). Figure 3 (d) indicates that while the crystallinity of the film made from the $0.01 \mathrm{wt} \%$ solution was almost that same as that made from the $0.05 \mathrm{wt} \%$ solution, the film became thinner. In fact, the measured thicknesses of semiconducting layers were $10 \mathrm{~nm}$ at $0.01 \mathrm{wt} \%$ and 60 $\mathrm{nm}$ at $0.05 \mathrm{wt} \%$. This observation indicates that the crystallinity of the semiconducting films strongly affected the electrical characteristics of the fabricated devices. Although the concentration of the semiconducting solution must be high enough to form a thick enough semiconducting layer for the carriers to conduct, too high a concentration makes this layer rough, which causes a decrease in mobility, increase in off current, and scatters the threshold voltages. Specifically, the thick films obtained from the $2 \mathrm{wt} \%$ solution (Figure 3(a)) made unfavorable current paths, and the carriers in the semiconducting layer could not be controlled by the gate voltage. These paths caused the off current to increase (Figure 2(a)). At high concentrations, solute gathered at a bank edge as a result of the coffee-ring effect, which caused the needle-like crystalline structures of semiconducting layer [29]. It has been reported that these needle-like structures confer high mobility if they bridge a channel region between the source and drain electrodes [30], but this time characteristic decreased because there were many crystal grain boundaries for the needle-like crystal to grow parallel to the source/drain electrodes. It has been reported that the transistor characteristic deteriorates if the organic semiconductor layer is thin [31]. Figure 3 shows that a concentration smaller than $0.05 \mathrm{wt} \%$ made the semiconducting films so thin that the films were insufficient for the channel region. It appears that the change in the threshold voltage was also affected by the crystallinity or thickness of the organic semiconducting layer. These results confirm that the optimum concentration is $0.05 \mathrm{wt} \%$. 


\subsection{Short channel transistor}

Figure 4 (a) shows the transfer characteristics of the TFT devices fabricated from a $0.05 \mathrm{wt} \%$ solution, having a short-channel-length (less than $10 \mu \mathrm{m}$ ), and with and without a SAM treatment to the source/drain electrodes. The SAM modification process dramatically improved the transistor electrical characteristics, whereby the on/off ratio increased from $1.6 \times 10^{4}$ to $2.9 \times 10^{5}$, the mobility in the saturation regime increased from $0.015 \mathrm{~cm}^{2} / \mathrm{Vs}$ to $1.2 \mathrm{~cm}^{2} / \mathrm{Vs}$, and threshold voltage shifted to $-1.0 \mathrm{~V}$ from 7.3 V. The following are possible causes for this good characteristic. The first is an appropriate level of crystallinity. As mentioned above, we confirmed the optimum concentration of organic semiconductor. The other is decreasing the injection barrier. This improved the carrier injection from the source/drain electrodes to the semiconducting layer. The SAM treatment changed the work function of the printed silver source/drain electrodes from $4.7 \mathrm{eV}$ to $5.4 \mathrm{eV}$ (see supporting figure $\mathrm{S} 1$ ). The work function of the SAM-treated source/drain electrodes is close to the HOMO level of the semiconducting layer used in this study. It seems that the SAM treatment dramatically reduces the contact resistance $\left(R_{\mathrm{C}}\right)$ and thereby improves the effective mobility. We estimated $R_{\mathrm{C}}$ of the fabricated TFT devices by using a transfer-line method (TLM) $[32,33]$ in an effort to verify the decrease in the injection barrier. Figure 4(d) shows the width-normalized $R_{\mathrm{C}}$ dependency on the gate voltage for the SAM-treated TFT devices. The obtained $R_{\mathrm{C}}$ was $4.1 \mathrm{k} \Omega \mathrm{cm}$ at $V_{\mathrm{GS}}=-20 \mathrm{~V}$, a remarkably low $R_{\mathrm{C}}$ value for solution-processed organic TFT devices, which causes the effective mobility of the fabricated TFT devices with a short channel length to be high. Additionally, the surface 
energy of the gate dielectric layers did not change after the SAM treatment (see Table S1).

We also evaluated the operational stability of the devices. We estimated the change in threshold voltage $\left(\Delta V_{\mathrm{TH}}\right)$ as the devices were stressed with constant bias voltages $\left(V_{\mathrm{GS}}=V_{\mathrm{DS}}=-20 \mathrm{~V}\right)$ from their transfer characteristics. Figure 5 (a) shows how $V_{\mathrm{TH}}$ changes over time when the devices were stressed with constant voltages. When a DC bias voltage of $-20 \mathrm{~V}$ was continuously applied to the TFTs for $10^{4} \mathrm{~s}$, the $V_{\mathrm{TH}}$ changed from $-0.41 \mathrm{~V}$ to $-0.78 \mathrm{~V}$, which corresponded to a $\Delta V_{\mathrm{TH}}$ of $-0.37 \mathrm{~V}$. Figure 5 (b) shows the transfer characteristics of the TFT devices before and after stressing the devices for $10^{4} \mathrm{~s}$. The origin of the shift by the DC bias stress is still controversial. We consider it to be related to the motion of ions in the organic layer.

\subsection{Inverter circuit}

We fabricated a diode-load inverter to determine the static and dynamic response of the circuits [34]. Figure 6 (a) shows a photograph of a fabricated inverter. The channel lengths of the both switching and resistor TFT devices were less than 10 $\mu \mathrm{m}$. W/L for the switching and resistor TFT devices was about 2:1. Narrow gate electrodes $(100 \mu \mathrm{m}$ width) were used to reduce the parasitic capacity of the transistor. The contact length $\left(L_{\mathrm{C}}\right)$ of the inverter is $100 \mu \mathrm{m}$. Figure 6(b) shows the static characteristics of the inverter. The plotted values are reasonable for a diode-load inverter [35]. Figure 6(c) and (d) shows the output behavior when the input voltage 
$\left(V_{\mathrm{IN}}\right)$ changed from low to high $(0 \mathrm{~V}$ to $20 \mathrm{~V})$ or high to low $(20 \mathrm{~V}$ to $0 \mathrm{~V})$ at a supply voltage $V_{\mathrm{DD}}=20 \mathrm{~V}$. The delay time is the sum of the rise and fall times, which are defined as the time difference between $10 \%$ and $90 \%$ of the output signal for transient changes in the circuit input from a logically low to high level (rise time), and vice versa (fall time). The measured rise and fall times were $t_{\mathrm{r}}=13 \mu \mathrm{s}$ and $t_{\mathrm{f}}=48 \mu \mathrm{s}$, which corresponded to a total delay time of $61 \mu \mathrm{s}$. Therefore, the maximum operating frequency was $8 \mathrm{kHz}$. Compared with other reports of ring oscillators that used printed TFTs, the operating frequency of this study is fast [36]. The short channel length and high effective mobility increased the operation speed of the printed organic circuits. Additionally, the small $L_{C}$ also led to fast operation; indeed, the operating frequency for a long contact length $\left(L_{\mathrm{C}}=250 \mu \mathrm{m}\right)$ was $4 \mathrm{kHz}$ (see Figure S3).

Though Kang et al. reported a printed short-channel organic TFT device with a cut-off frequency of $300 \mathrm{kHz}$ [22], this value was estimated from only one transistor and is different from the operating frequency obtained from the results described here. The operating frequency determined from our results is more accurate for estimating the operation speed of integrated circuits because our results were obtained from input-output characteristics of inverter circuits.

We achieved printed organic TFT devices that have a printed semiconducting layer and source/drain electrodes, short channel length (less than $10 \mu \mathrm{m}$ ), high mobility (more than $1.0 \mathrm{~cm}^{2} / \mathrm{Vs}$ ), high on/off ratio (more than $10^{5}$ ), and high operation stability. 
Though there are several reports on printed short-channel transistors [22-24, 37], those devices lack at least one of the above key parameters for printed electronics. Though it is true that two issues remain, i.e., devising scalable methods for the short-channel region and decreasing the overlap capacitance for the printed gate electrodes, these issues can be resolved by establishing printing technologies.

\section{CONCLUSION}

In summary, we fabricated organic TFT devices with a short channel length and printed source/drain electrodes by using organic semiconductor in solution. We confirmed that the mobility, threshold voltage, and on/off ratio changed with the concentration of the organic semiconductor solution. We found that a short channel leading to higher mobility could be fabricated by using SAM processing and optimal concentrations of organic semiconductor. Furthermore, the fabricated devices were very stable versus a DC bias. In addition, an inverter circuit with excellent transfer characteristics was realized. The maximum operating frequency of the inverter circuit was $8 \mathrm{kHz}$ for $V_{\mathrm{DD}}=20 \mathrm{~V}$. These results demonstrate the excellent performance of organic TFTs with a short channel length.

\section{ACKNOWLEDGEMENTS}


This study was supported by the Japan Science and Technology Agency (JST) and a Grant-in-Aid for Scientific Research (KAKENHI; WAKATE B, Grant number 25820134). We thank Merck for providing the materials (lisicon ${ }^{\circledR}$ S1200) and DIC Corporation for providing silver nanoparticle ink (JAGLT-01). 


\section{REFERENCES}

[1] M. Kaltenbrunner, T. Sekitani, J. Reeder, T. Yokota, K. Kuribara, T. Tokuhara, M.

Drack, R. Schwödiauer, I. Graz, S. Bauer-Gogonea, S. Bauer, T. Someya, Nature 499 (2013) 458.

[2] K. Fukuda, Y. Takeda, Y. Yoshimura, R. Shiwaku, L. T. Tran, T. Sekine, M. Mizukami, D. Kumaki, and S. Tokito, Nat. Commun. 5 (2014) 4147.

[3] J. A. Rogers, Z. Bao, K. Baldwin, A. Dodabalapur, B. Crone, V. R. Raju, V. Kuck, H. Katz, K. Amundson, J. Ewing, and P. Drzic, Proc. Natl. Acad. Sci. USA 98 (2001) 4835.

[4] S. Steudel, K. Myny, S. Schols, P. Vicca, S. Smout, A. Tripathi, B. vander Putten, J. van der Steen, M. van Neer, F. Schutze, O. R. Hild, E. van Veenedaal, P. van Lieshout, M. van Mill, J. Genoe, G. Gelinck, Paul Heremans, Org. Electron. 13 (2012) 1729.

[5] M. Noda, N. Kobayashi, M. Katsuhara, A. Yumoto, S. Ushikura, R. Yasuda, N. Hirai, G. Yukawa, I. Yagi, K. Nomoto, T. Urabe, J. Soc. Inf. Display 19 (2011) 316.

[6] T. Someya, Y. Kato, S. Iba, Y. Noguchi, T. Sekitani, H. Kawaguchi, T. Sakurai, IEEE Trans, Electron Device 52 (2005) 2502.

[7] Y. Kato, T. Sekitani, Y. Noguchi, T. Yokota, M. Takamiya, T. Sakurai, T. Someya, IEEE Trans. Electron Devices 57, (2010)995.

[8] M. Zirkl, A. Fian, H. Schon, C. Sommer, G. Jakopic, G. Leising, B. Stadlober, I. Graz, N. Gaar, R. Schwodiauer, S. Bauer-Gogonea, S. Bauer, Adv. Mater. 19 (2007) 2241. 
[9] K. Myny, S. Steudel, S. Smout, P. Vicca, F. Furthner, B. van der Putten, A. K. Tripathi, G. H. Geliinck, J. Genoe, W. Dehaene, P. Heremans, Org. Electron. 11 (2011) 1176.

[10] E. Cantatore, T. C. T. Geuns, G. H. Gelinck, E. van Veenendaal, A. F. A. Gruijthuijsen, L. Schrijnemakers, S. Drews, D. M. de Leeuw, IEEE J. Solid-State Circuits 42 (2007) 84.

[11] T.-C. Huang, K. Fukuda, C.-M. Lo, Y.-H. Yeh, T. Sekitani, T. Someya, K.-T. Cheng, IEEE Trans. Electron Devices 58 (2011) 141.

[12] K. Fukuda, T. Sekine, Y. Kobayashi, Y. Takeda, M. Shimizu, N. Yamashita, D. Kumaki, M. Itoh, M. Nagaoka, T. Toda, S. Saito, M. Kurihara, M. Sakamoto, S. Tokito, Org. Electron. 13 (2012) 3296.

[13] Y. Takeda, Y. Yoshimura, Y. Kobayashi, D. Kumaki, K. Fukuda, S. Tokito, Organic Electronics 14 (2013) 3362.

[14] I. Nausieda, K. K. Ryu, D. D. He, A. I. Akinwande, V. Bulovi'c, C. G. Sodini, IEEE Trans. Electron Devices 57 (2010) 3027.

[15] D. Bode, K. Myny, B. Verreet, B. van der Putten, P. Bakalov, S. Steudel, S. Smout, P. Vicca, J. Genoe, P. Heremans, Appl. Phys. Lett. 96 (2010) 133307.

[16] M. Kitamura, Y. Kuzumoto, S. Aomori, Y. Arakawa, Appl. Phys. Express 4 (2011) 051601.

[17] B. Crone, A. Dodabalapur, Y.-Y. Lin, R. W. Filas, Z. Bao, A. LaDuca, R. 
Sarpeshkar, H. E. Katz, W. Li, Nature 403 (2000) 521.

[18] H. Fuketa, K. Yoshioka, T. Yokota, W. Yukita, M. Koizumi, M. Sekino, T. Sekitani, M. Takamiya, T. Someya, T. Sakurai, IEEE ISSCC Dig. Tech. Papers (2014) 490.

[19] F. Ante, D. Kalblein, T. Zaki, U. Zschieschang, K. Takimiya, M. Ikeda, T. Sekitani, T. Someta, J. N. Burghartz, K. Kern, H. Klauk, Small 8 (2012) 73.

[20] K. Myny, S. Steudel, S. Smout, P. Vicca, F. Furthner, B. van der Putten, A. K. Tripathi, G.H. Gelinck, J. Genoe , W. Dehaene, P. Heremans, Org. Electron. 11 (2010) 1176.

[21] M. Kitamura, Y. Arakawa, Jpn. J. Appl. Phys. 50 (2011) 01BC01 .

[22] H. Kang, R. Kitsomboonloha, J. Jang, V. Subramanian, Adv. Mater. 24 (2012) 3065 .

[23] K. Suzuki, K. Yutani, M. Nakashima, A. Onodera, S. Mizukami, M. Kato, T. Tano, H. Tomono, M. Yanagisawa, K. Kameyama, Proc. IDW 09 (2009) 1581.

[24] C. W. Sele, T. von Werne, R. H. Frend, H. Sirringhaus, Adv. Mater. 17 (2005) 997.

[25] K. Fukuda, Y. Takeda, M. Mizukami, D. Kumaki, S. Tokito, Sci. Rep. 4 (2014) 3947 .

[26] G. Lloyd, T. Backlund, P. Brookes, L. W. Tan, P. Wierzchowiec, S. Bain, J.-Y. Lee, M. James, J. Canisius, S. Tierney, K. Kawamata, T. Wakimoto, Proc. IDW 10 (2010) 
469.

[27] M. Jamesn, I. Afonina, T. Bäcklund, S. Bain, P. Brookes, G. Lloyd, P. Miskiewicz, L.-W. Tan, P. Wierzchowiec, M. Verrall, SID Int. Symp. Dig. Tec. 43 (2012) 422.

[28] Y. Fujisaki, H. Ito, Y. Nakajima, M. Nakata, H. Tsuji, T. Yamamoto, H. Furue, T. Kurita, N Shimidzu, Appl. Phys. Lett. 102 (2013) 153305.

[29] R. D. Deegan, O. Bakajin, T. F. Dupont, G. Huber, S. R. Nagel, T. A. Witten, Nature 389 (1997) 827.

[30] A. B. Naden, J. Loos, D. A. MacLaren, J. Mater. Chem. C, 2 (2014) 245.

[31] Y. Diao, B. C-K. Tee, G. Giri, J. Xu, D. H. Kim, H. A. Becerril, R. M. Stoltenberg, T. H. Lee, G. Xue, S. C. B. Mannsfeld, Z. Bao. Nat. Mater. 12 (2013) 665-671.

[32] D. Guo, T. Miyadera, S. Ikeda, T. Shimada, K. Saiki. J. Appl. Phys. 102 (2007) 023706.

[33] D. Gundlach, L. Zhou, J. Nichols, T. Jackson, P. Necliudov, and M. Shur, J. Appl. Phys. 100 (2006) 024509.

[34] H. Klauk, G. Schmid, W. Radlik, W. Weber, L. Zhou, Chris D. Sheraw, J. A. Nichols, T. N. Jackson, Solid-State Electron. 47 (2003) 297.

[35] J. Smith, R. Hamilton, M. Heeney, D. M. de Leeuw, E. Cantatore, J. E. Anthony, I. McCulloch, D. D. C. Bradley, and Thomas D. Anthopoulos, Appl. Phys. Lett. 93 (2008) 253301. 
[36] A. C. Huebler, F. Doetz, H. Kempa, H.E. Katz, M. Bartzsch, N. Brandt, I. Hennig, U. Fuegmann, S. Vaidyanathan, J. Granstrom, S. Liu,A. Sydorenko, T. Zillger, G. Schmidt, K. Preissler, E. Reichmanis, P. Eckerle, F. Richter, T. Fischer, U. Hahn, Org. Electron. 8 (2007) 480.

[37] M. M. Voigt, A. A. Guite, D. Y. Chaung, R. U. A. Khan, A. J. Campbell, D. D. C. Bradley, F. Meng, J. H. G. Steinke, S. Tierney, I. McCulloch, H. Penxten, L. Lutsen, O. Douheret, J. Manca, U. Brokmann, K. Sonnichsen, D. Hulsenberg, W. Bock, C. Barron, N. Blanckaert, S. Springer, J. Grupp, and A. Mosley, Adv. Funct. Mater. 20 (2010) 239. 


\section{Figure captions}

\section{Figure 1. Organic TFT devices with printed electrodes.}

(a) Illustration of a fabricated organic TFT device. (b) Photograph of the organic TFT device. (c) Photograph of the source/drain electrodes.

Figure 2. Organic TFT characteristics depending on organic semiconductor concentration.

(a) Transfer characteristics for each organic semiconductor concentration. (b-d) Change in (b) mobility, (c) threshold voltage, and (d) ON/OFF ratio with concentration of organic semiconductor.

Figure 3. Photograph of organic semiconductor crystal.

Photograph of organic semiconductor crystal made with solution concentrations of (a) $2 \mathrm{wt} \%$, (b) $0.1 \mathrm{wt} \%$, (c) $0.05 \mathrm{wt} \%$, and (d) $0.01 \mathrm{wt} \%$.

Figure 4. Organic TFT characteristics changed by SAM treatment.

(a-c) Transfer and output characteristics of TFTs with and without SAM treatment. (d) The gate voltage dependence of contact resistance in the TFT with SAM treatment. 


\section{Figure 5. DC bias stress of TFT with SAM.}

(a) Threshold voltage as a function of time during continuous DC bias stress of the TFT with SAM. (b) The corresponding transfer characteristics for a TFT with SAM device taken before and after applying a DC bias voltage for $10^{4} \mathrm{~s}$.

\section{Figure 6. Printed organic inverter circuit with short channel length.}

(a) Optical image of fabricated inverter circuit. (b) Transfer curve of the inverter at supply voltages of 4, 8,12,16, and $20 \mathrm{~V}$. (c-d) Output behavior when the output signal changes from low to high, i.e., the rising edge (c); changes from high to low, I.e., the falling edge $(\mathrm{d})$, at $\mathrm{V}_{\mathrm{DD}}=20 \mathrm{~V}$. The values were normalized to the maximum output value. 
(a)

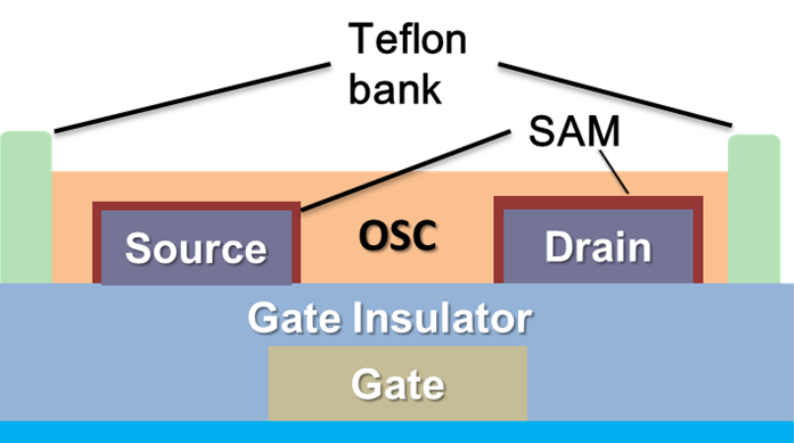

(b)

(c)

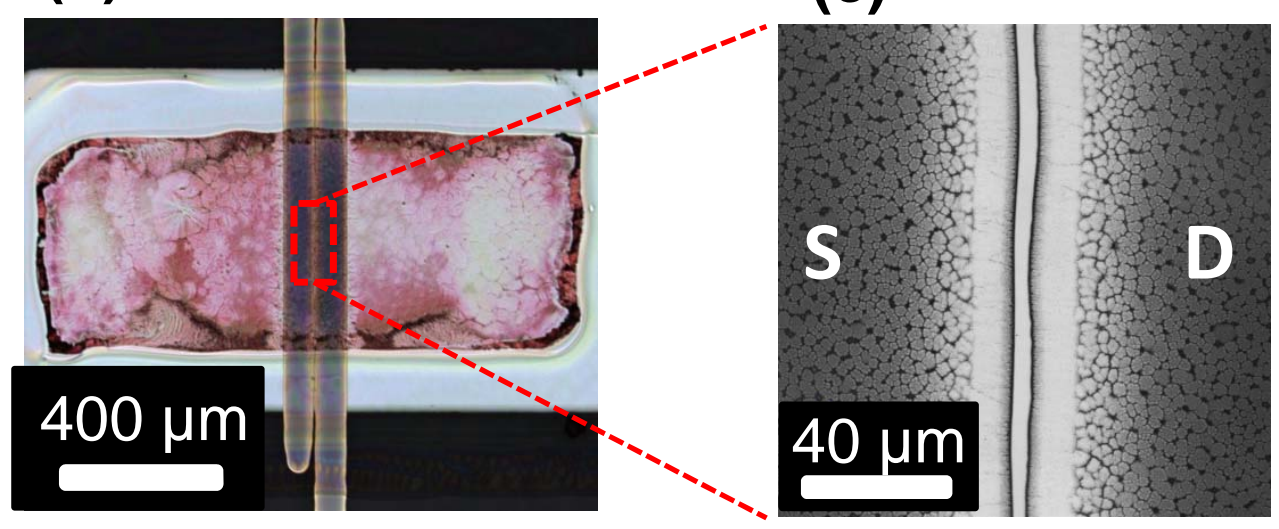

Yoshimura et al., Figure 1 
(a)

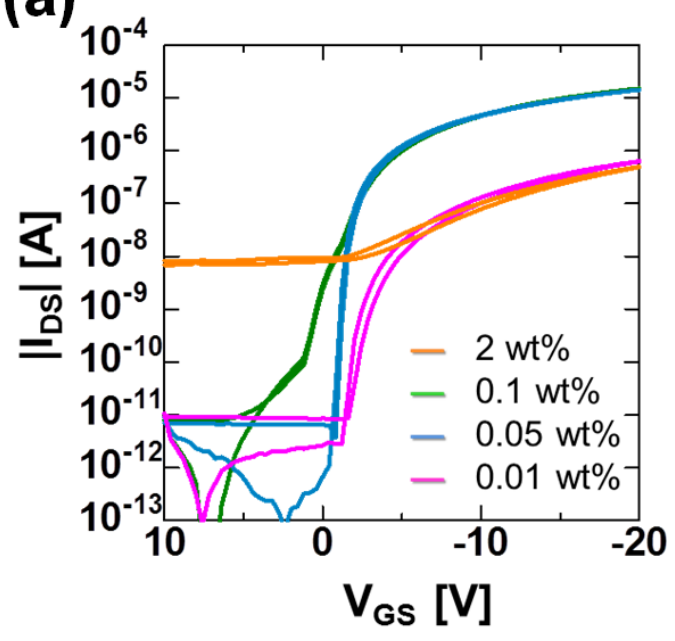

(c)

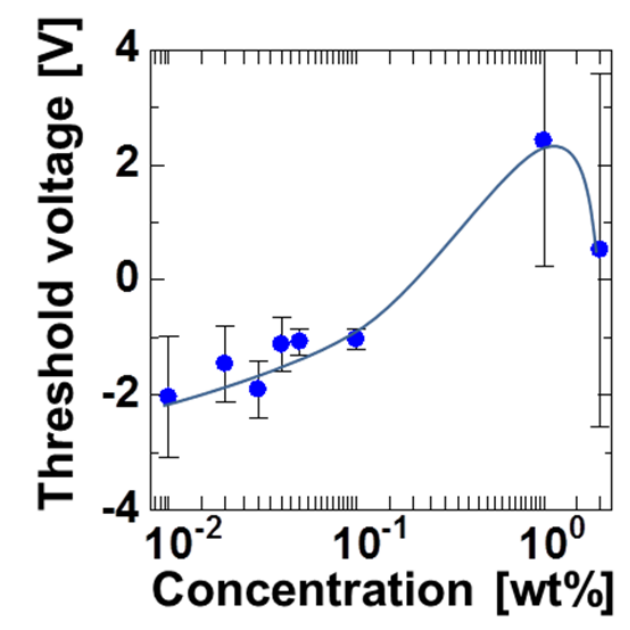

(b)

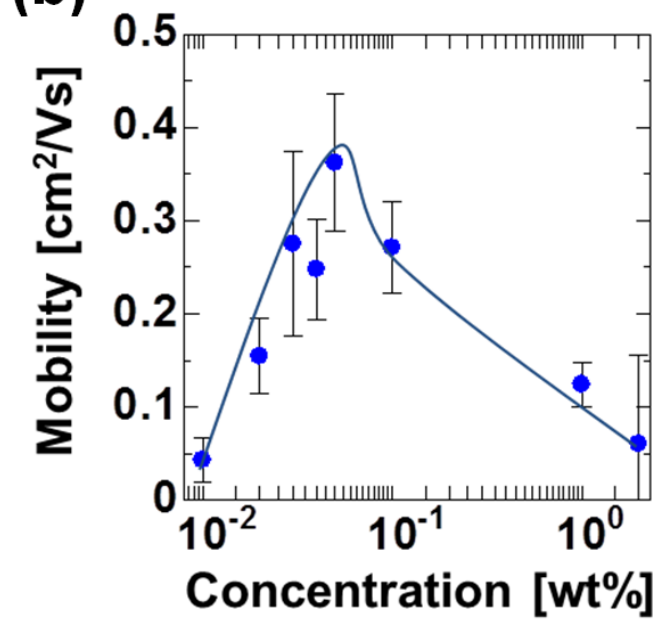

(d)

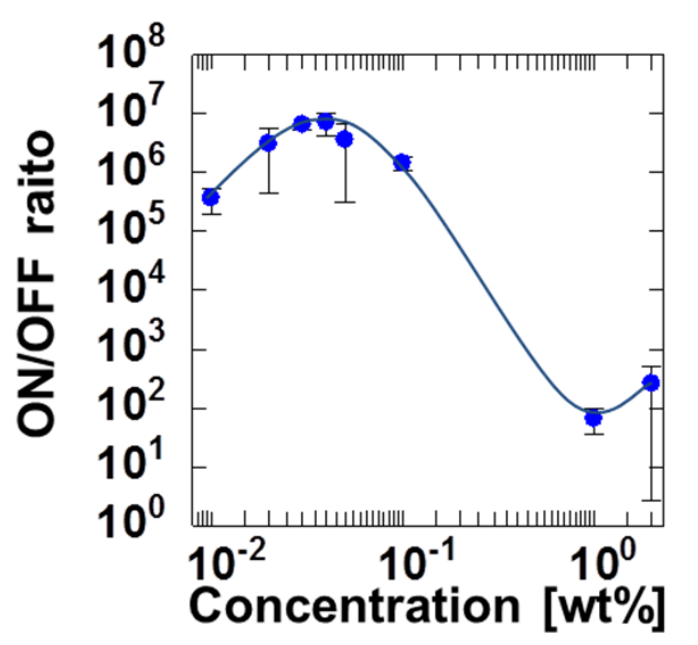

Yoshimura et al., Figure 2 
(a)

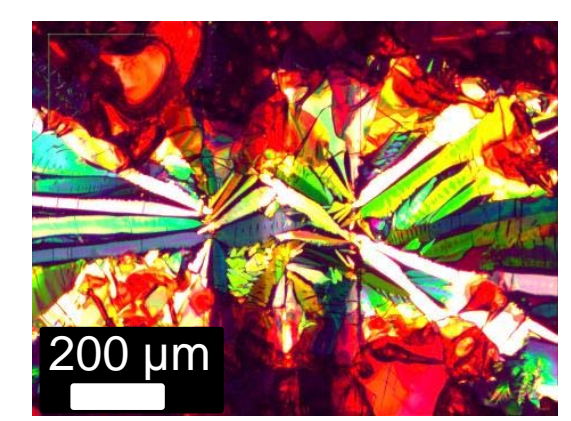

(c)

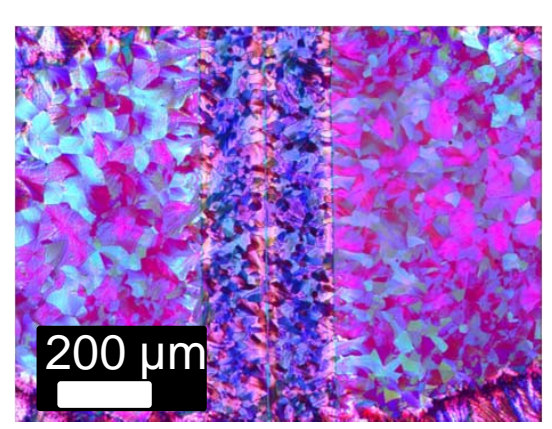

(b)

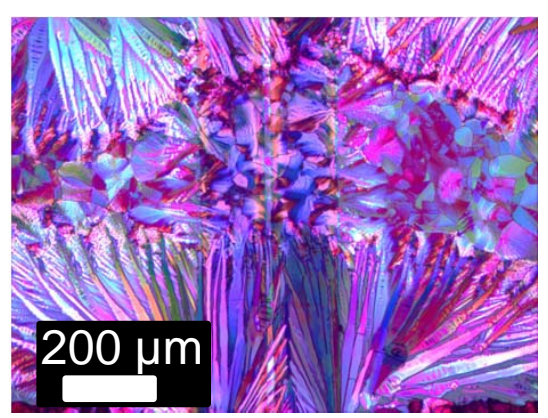

(d)

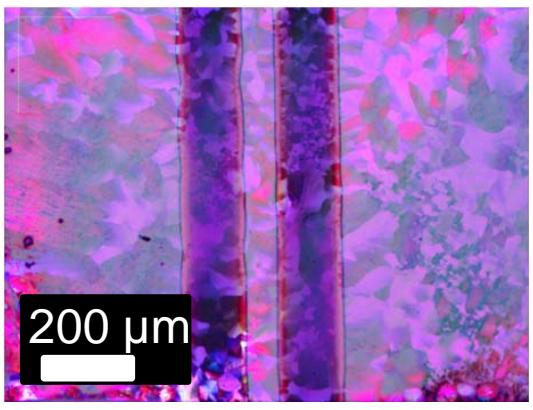

Yoshimura et al., Figure 3 
(a)
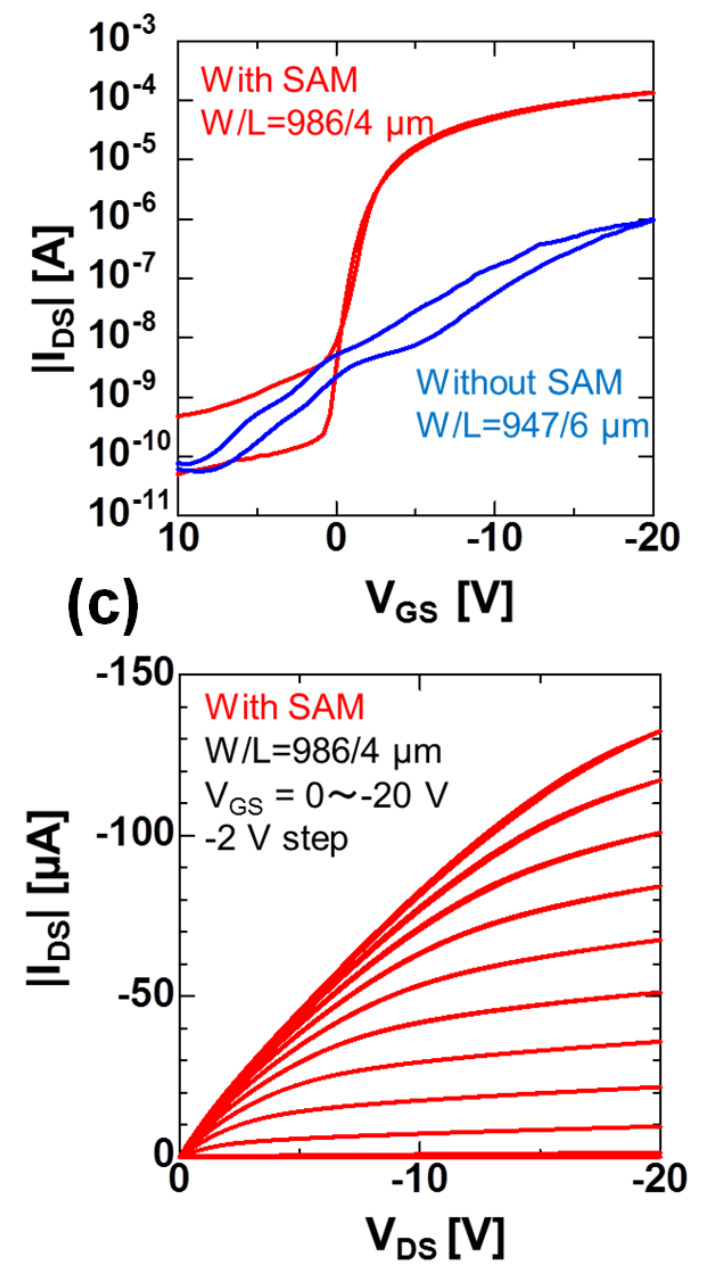

(b)
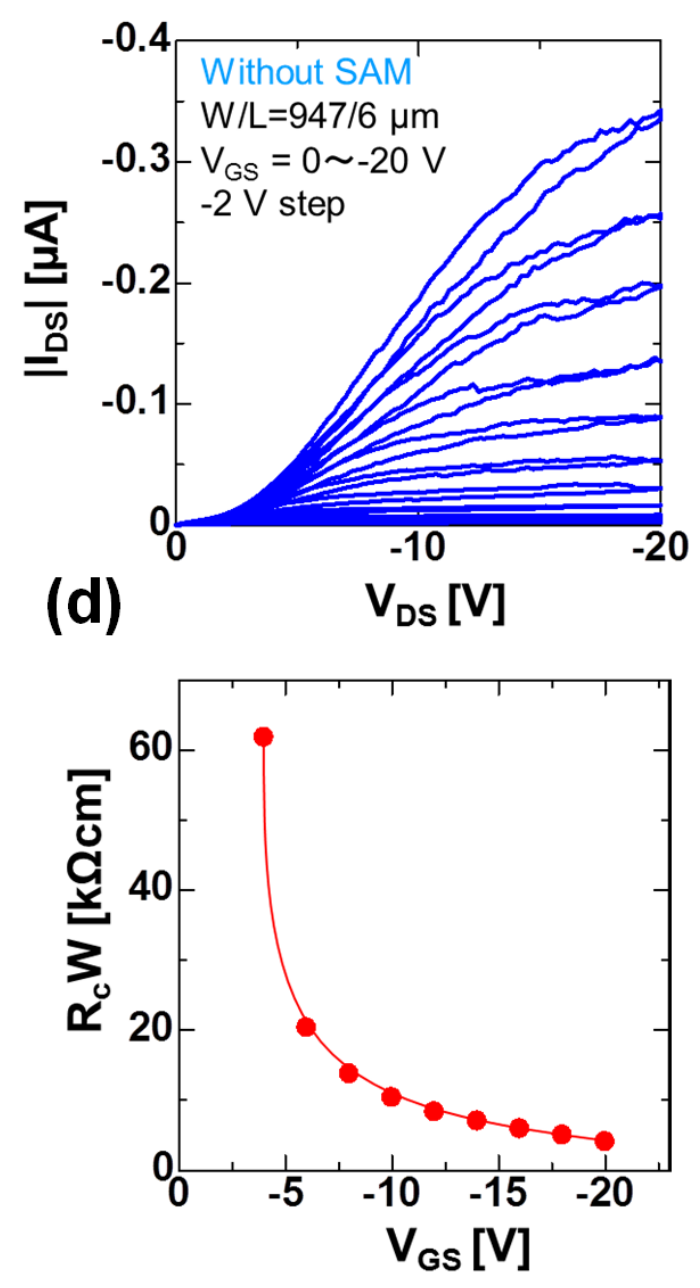

Yoshimura et al., Figure 4 
(a)

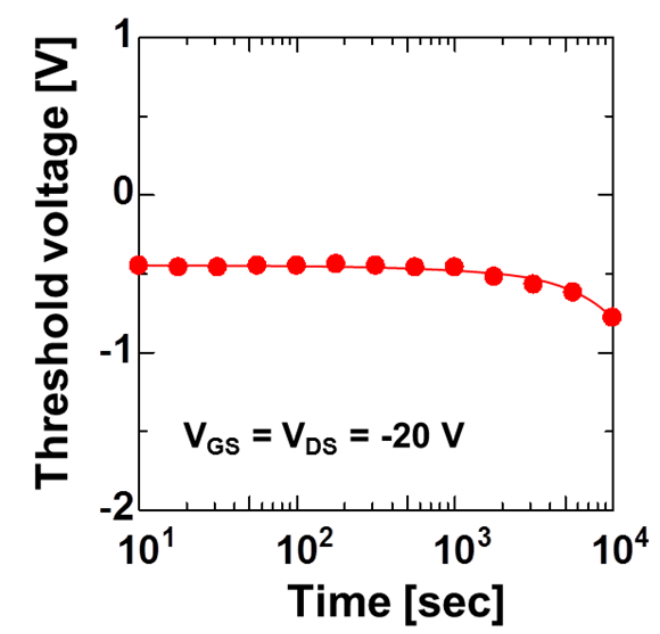

(b)

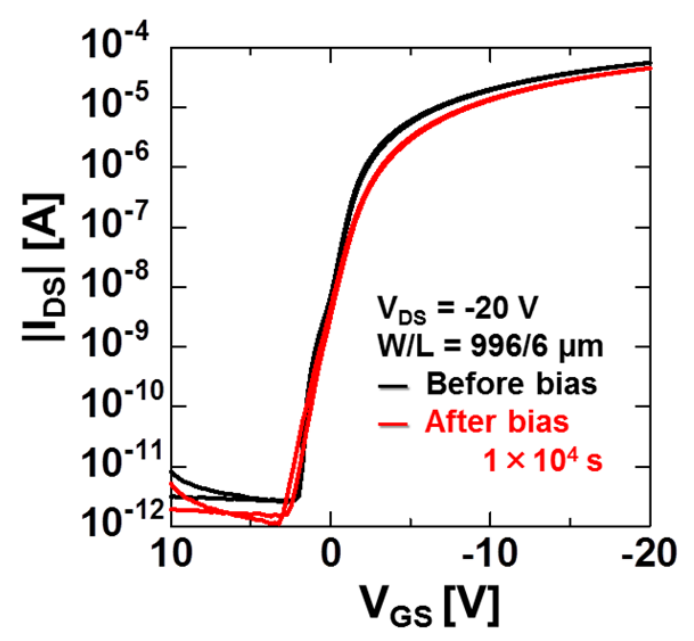

Yoshimura et al., Figure 5 
(a)

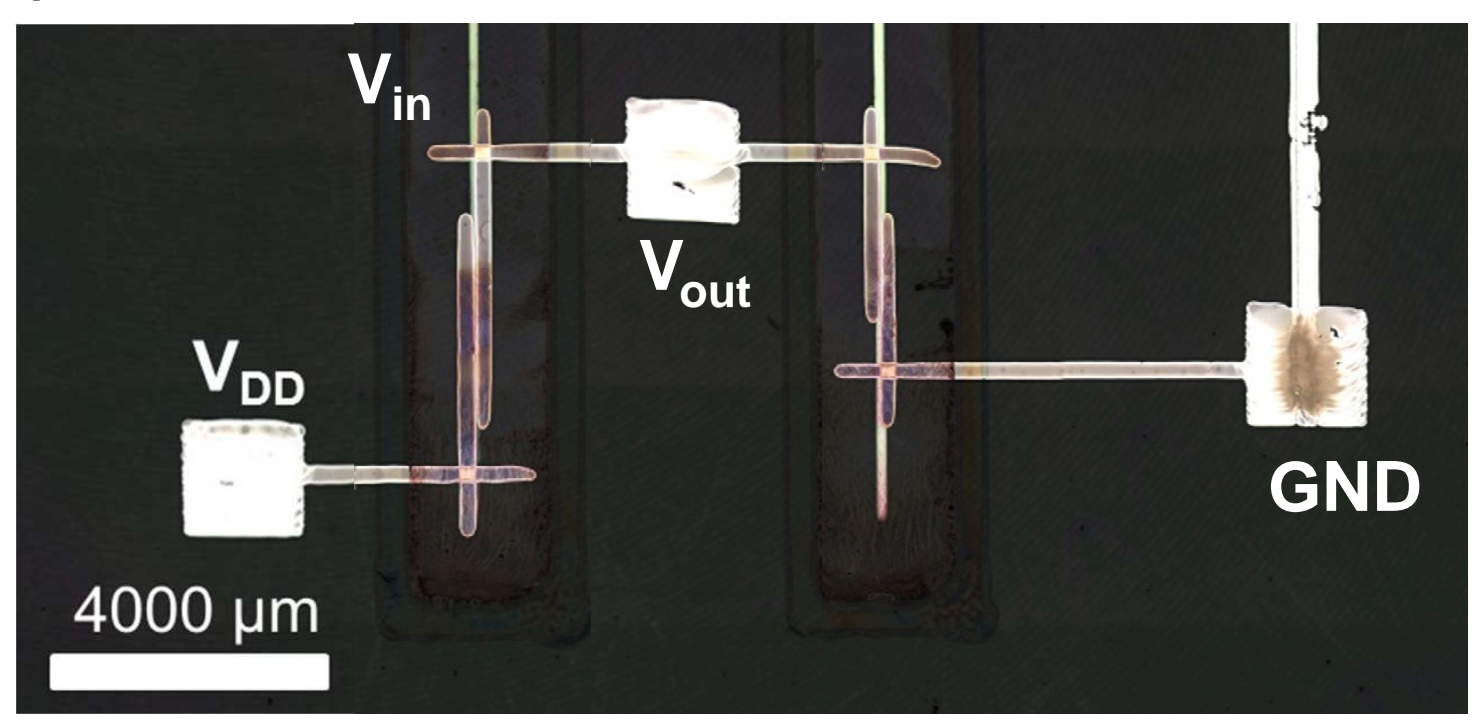

(b)

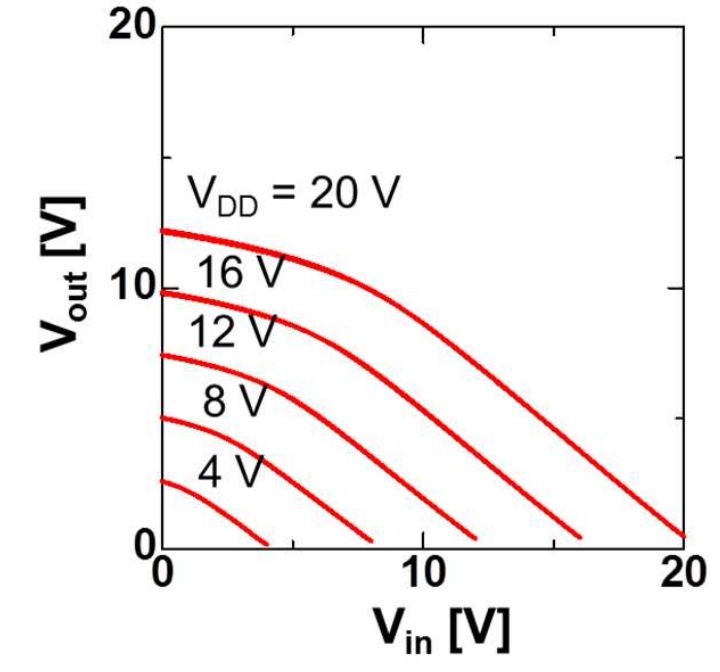

(c)

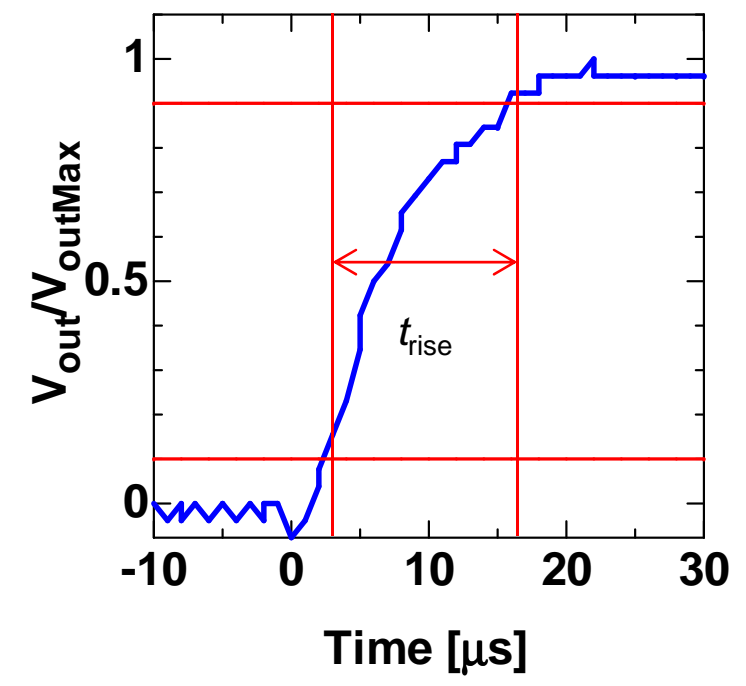

(d)

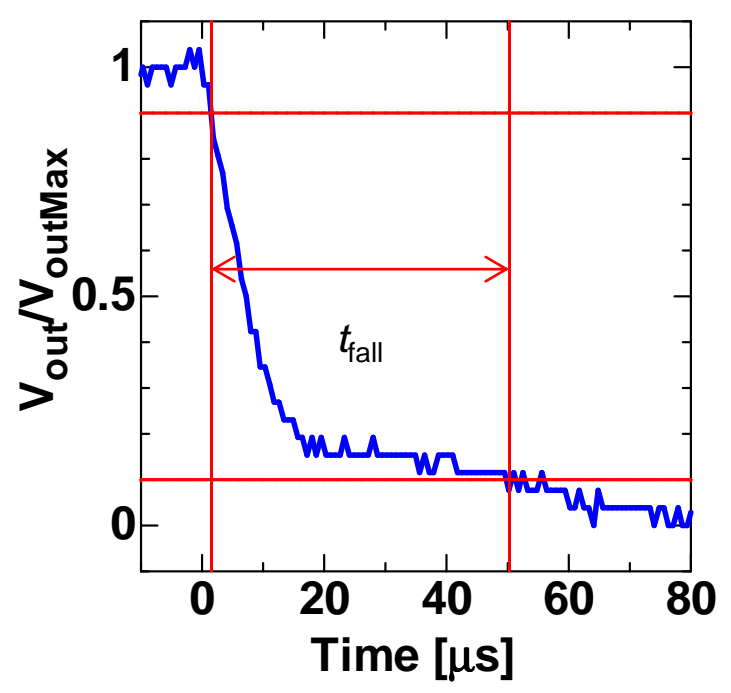

Yoshimura et al., Figure 6 

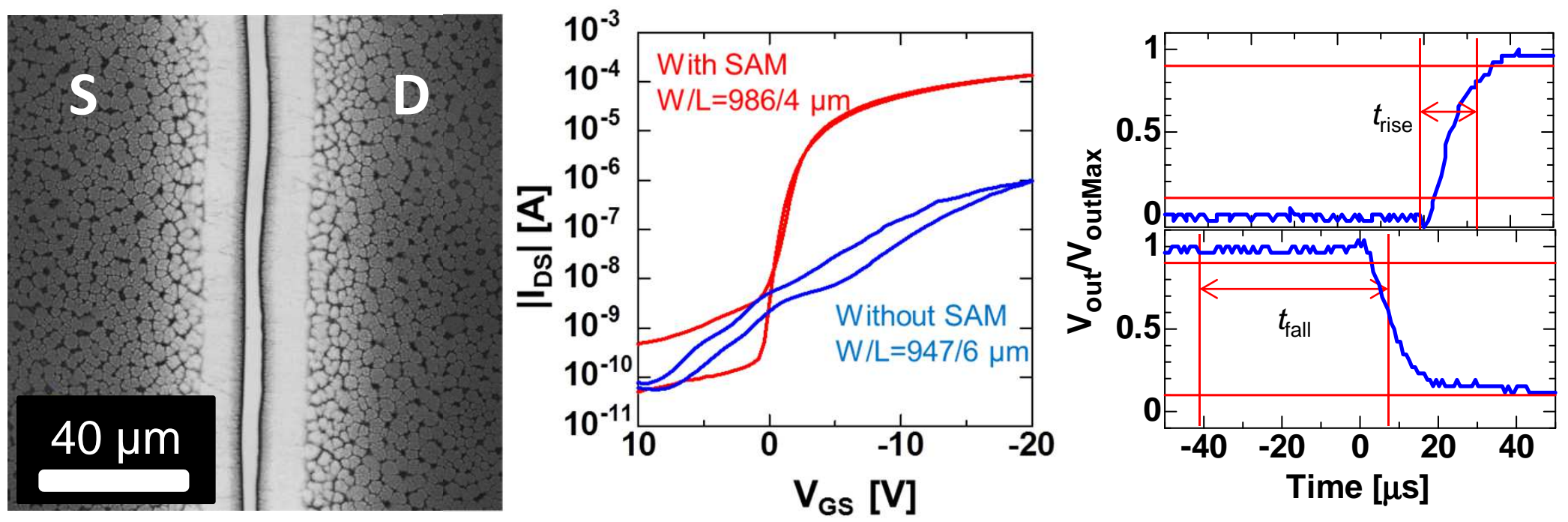